\title{
E-Motions: Assessing Emotional Quotient of Adolescents During Pandemic
}

\author{
Meenu Mathur Jha \\ Amity International School, Uttar Pradesh, India \\ meenumathurjha@gmail.com
}

\section{ABSTRACT}

The coronavirus COVID 19 pandemic is the defining global health crisis of our time and greatest challenge we have faced since World War two. This study aims to assess the Emotional quotient of adolescents during pandemic by studying the affect on each attribute of Emotional Intelligence and also to study the reason behind the decreased elements of emotional intelligence during Pandemic. The study of this project started with two surveys. In first Survey, the child had to assess whether the pandemic has had positive/negative/no impact on him/her in the respective areas by comparing with pre-lockdown experiences. Second Survey was conducted for Parents. The test was for measuring Emotional Intelligence of their children with regards to the coronavirus pandemic. Both the survey was conducted on Google Forms with more than 150 responses from students of grade 10 to grade12 studying in Delhi NCR and their parents. The results of all the surveys suggests that all attributes of Emotional Intelligence have shown increase except one major attribute- Self Regulation, which has undergone a decrease during pandemic. Some elements like Commitment, diversity, Communication have deceased during these crucial times. But adolescents have been able to navigate their emotions well during this tough times. Increased levels of empathy, optimism shows that this pandemic has opened our hearts, made us more sensitive to others and our environment.

Keywords: adolescents, pandemic, behaviour, self-regulation, empathy

Cite this article as: Mathur Jha, M. (2021). E-Motions: Assessing Emotional Quotient of Adolescents During Pandemic, International Journal of Higher Education Pedagogies, 2 (1), 10-18. https://doi.org/10.33422/ijhep.v2i1.56

\section{Introduction}

The coronavirus COVID 19 pandemic is the defining global health crisis of our time and greatest challenge we have faced since World War two. But the pandemic is much more than a health crisis, it is an unprecedented emotional crisis.

It has affected millions of lives worldwide, not only physically but also emotionally in the form of panic attacks, obsessional behavior, anxiety, and fear. Malbehavior has been appeared such as selfishness and storing goods which affected social cohesion and national income.

\subsection{What is the relation between Adolescence and Emotions?}

Adolescence is a transitional stage of physical and psychological development that generally occurs during the period from puberty to legal adulthood. Adolescence is usually associated with the teenage years, but its physical, psychological or cultural expressions may begin earlier and end later.

(C) The Author(s). 2021 Open Access. This article is distributed under the terms of the Creative Commons Attribution 4.0 International License, which permits unrestricted use, distribution, and redistribution in any medium, provided that the original author(s) and source are credited. 
Stressors experienced during this crucial developmental stage may affect the trajectory of this neural maturation and contribute to the increase in psychological morbidities, such as anxiety and depression, often observed during adolescence.

In addition to depression or anxiety, adolescents with emotional disorders can also experience excessive irritability, frustration or anger. Symptoms can overlap across more than one emotional disorder with rapid and unexpected changes in mood and emotional outbursts.

\subsection{What is Emotional Intelligence?}

When it comes to happiness and success in life, emotional intelligence matters just as much as intellectual ability.

The very root of the word emotion is moterre, the latin verb "to move" plus the prefix "e" to connote "move away", suggesting that a tendency to act is implicit in every emotion. All emotions are, in essence, impulses to act, the instant plans for handling life that evolution has instilled in us (Goleman, 2013).

Emotional Intelligence is the ability to understand, use and manage your emotions in positive ways to relieve stress, communicate effectively, empathize with others, overcome challenges and defuse conflict. People with high degree of Emotional Intelligence know what they are feeling, what their emotions mean and how these emotions can affect other people (Salovey and Mayer, 1990).

For most people, Emotional Intelligence (EQ) is more important than one's intelligence(IQ) in attaining success in their lives and careers. High IQ can predict high scores, a high EQ can predict success in social and emotional situation. As individuals our success and success of the profession today depend on our ability to read other people's signals and react appropriately to them (Goleman, 2013).

Therefore, each one of us must develop the mature Emotional Intelligence skills required to better understand, empathize and negotiate with other people - particularly as the economy has become more global. Otherwise, success will elude us in our lives and careers

\subsection{What are the various attributes of Emotional Intelligence?}

As per Daniel Goleman, Emotional Intelligence has five attributes;

\section{- Self-Awareness}

The ability to recognize an emotion as it "happen" is the key to our EQ. Developing selfawareness requires tuning into your true feelings. The major elements of self-awareness are;

- Emotional Awareness: Our ability to recognize our emotions and their effects.

- Self Confidence: Sureness about our self-worth and capabilities

- Self-Awareness: Our ability to know ourselves better, our likes and dislikes, what job to take, whom to marry.

\section{- Self-Regulation}

We experience only six major emotions- anger, sadness, fear, happiness, surprise and disgust. We often have little control over when we experience emotions. But we can however, have some say in how long an emotion will last such as anger, anxiety etc. Self Regulation involves: 
- Self-Control: Managing disruptive emotions

- Trustworthiness: Maintaining standards of honesty and integrity.

- Conscientiousness: Taking responsibility for own performance

- Adaptability: Handling change with flexibility

- Innovation: Being open to new ideas

- Motivation

To activate ourselves for any achievement requires clear goals and a positive attitude. Motivation involves;

- Achievement drive: Our constant striving to improve or to meet standard of excellence.

- Commitment: Aligning with the goals of the group or organisation

- Initiative: Readying ourselves to act on opportunities

- Optimism: Pursuing goals persistently despite obstacles and setbacks

- Empathy

The ability to recognize how people feel is important to success in our life and career. An empathetic person excels at;

- Service Orientation: Anticipating and recognizing the needs of others.

- Developing Others: Sensing what others need to progress and bolstering their abilities

- Leveraging Diversity: Cultivating opportunities through diverse people.

- Understanding Others: Discerning the feelings behind the needs and wants of others.

- Social Skills

The development of good interpersonal skills is tantamount to success in our lives and career. People skills are more important now because we must possess a high EQ to understand, empathize and negotiate with others in global economy. Important useful skills are;

- Influence: Wielding effective persuasion tactics

- Communication: Sending clear messages

- Leadership; Inspiring and guiding people

- Conflict management: Understanding, negotiating and resolving disagreements

- Building Bonds: Nurturing instrumental relationships

- Collaboration and Cooperation: Working in group towards common goals

- Team capabilities: Creating group synergy in pursuing common goals.

The concept of Emotional Intelligence is atop topic among today's modern adolescents. It is the young people of today that will make up the workplace of tomorrow.

A person's level of EQ is more important than their IQ, it is effective predictor for success and overall happiness (Goleman, 2013).

2. Aim

- To assess the Emotional quotient of adolescents during pandemic by studying the affect on each attribute of Emotional Intelligence

- To study the reason behind the decreased elements of emotional intelligence during Pandemic. 


\section{Methodology}

The study of this project started with contrasting behaviour of two students during Online classes in this Covid era.

\subsection{Case Study-1}

' $\mathrm{X}$ ', student of grade 10, was brilliant in studies, very disciplined, sincere, punctual, respectful and polite. During lockdown, school organised a Global Webinar on Zoom. It was attended by more than thousand students and teachers. Student ' $\mathrm{X}$ ' also registered for the same but with a pseudonym. He gave his name as ' $y$ ', a student of his own class.

As the webinar started, he typed abusive words for school heads, showing identity as student ' $\mathrm{Y}$ ' in the chat box which everyone read. All were shocked to see them. After lot of efforts, it was traced that student ' $\mathrm{X}$ ' had written all those abusive messages.

Student ' $\mathrm{X}$ ' was called to school to accept his mistake. But he was not ready to accept it. After a thorough interrogation, he however confessed.

The question arises, why a child who was academically brilliant, had no prior discipline issues and was very polite in his conduct would indulge in something that could count as Cybercrime.

\subsection{Case Study-2}

'A', student of grade 9, was introvert, had high IQ, remained busy in his books, disciplined and sincere. During lockdown, when all classes were taken online by teachers, someone played music repeatedly interrupting the class again and again for days in continuation.

After lot of efforts of tech department and thorough investigation, student 'A' name was revealed. Initially he did not admit of committing this mistake but later confessed.

Again, the question arises, why an introvert child, who had no prior complaints against him could commit such a mistake.

The above two incidents made me wonder why students who according to school were brilliant in their studies, very disciplined, sincere, respectful were involved in such acts of immorality.

When spoken to both of them, they had no concrete reasons behind their actions.

\subsection{Method of the Study}

In the present study, the normative method is employed. The normative method is used to describe and interpret what exists at present. It is concerned with the condition of relationships that exist, practices that prevail, beliefs, points of review, or attitudes that are held, ongoing processes, and effects that are being felt.

The present study focuses on data collected by conducting two surveys.

Moreover, the study is based on the cross-sectional survey, intended to gather information on a population at a single point of time.

Sample Size: 150 students of grade 10 to grade 12 studying in the city.

First Survey was conducted to measure Emotional Intelligence of students with regard to the coronavirus pandemic and subsequent changes observed in the educational pattern. The child had to assess whether the pandemic has had positive (increase) /negative (decrease) /no impact on him/her in the respective areas by comparing with pre-lockdown experiences. 
The survey had 20 multiple choice questions related to different attributes of Emotional Intelligence and was conducted via Google Forms.

Second Survey was conducted for Parents. The aim and setting of the test remained the same as that of the first survey except this time, the parents had to assess whether they have observed positive/negative/no change in the child during lockdown by comparing their current behavioural and mental attributes with their pre-lockdown counterparts.

The survey had 20 multiple choice questions to be answered by parents and was conducted on Google Forms.

\section{Observations and Analysis}

As each question of the survey was related to a particular element of an Attribute of Emotional Intelligence, hence percentage increase / decrease/ no change was tabulated.

Mean increase/decrease/ no change percentage for each Attribute was then calculated for students and parents separately and then together.

\subsection{Self-Awareness}

By students:

Table 1.

Percentage change in various elements of Self Awareness in students

\begin{tabular}{lccc}
\hline \multicolumn{1}{c}{ ELEMENTS } & INCREASE & DECREASE & NO CHANGE \\
\hline Emotional Awareness & $56.7 \%$ & $37 \%$ & $6.3 \%$ \\
Self-Assessment & $53.6 \%$ & $30 \%$ & $16.4 \%$ \\
Self Confidence & $56.4 \%$ & $35 \%$ & $7.9 \%$ \\
Mean $\%$ & $55.5 \%$ & $34 \%$ & $6.8 \%$ \\
\hline
\end{tabular}

By parents:

Table 2.

Percentage change in various elements of Self Awareness in students observed by parents

\begin{tabular}{lccc}
\multicolumn{1}{c}{ ELEMENTS } & INCREASE & DECREASE & NO CHANGE \\
\hline Emotional Awareness & $50.5 \%$ & $30.4 \%$ & $19.4 \%$ \\
Self-Assessment & $50 \%$ & $32 \%$ & $18 \%$ \\
Self Confidence & $59.7 \%$ & $34.6 \%$ & $5.7 \%$ \\
Mean \% & $53.4 \%$ & $32.3 \%$ & $14.2 \%$ \\
\hline
\end{tabular}

\subsection{Self-Regulation}

By Students:

Table 4.

Percentage change in various elements of Self-Regulation in students

\begin{tabular}{lccc}
\hline \multicolumn{1}{c}{ ELEMENTS } & INCREASE & DECREASE & NO CHANGE \\
\hline Trustworthiness & $39.6 \%$ & $51.1 \%$ & $9.3 \%$ \\
Adaptability & $46.4 \%$ & $38.5 \%$ & $15.1 \%$ \\
Conscientiousness & $48.7 \%$ & $41.2 \%$ & $10.1 \%$ \\
Innovativeness & $55.4 \%$ & $39.6 \%$ & $5 \%$ \\
Seif Control & $27 \%$ & $60 \%$ & $13 \%$ \\
Mean $\%$ & $43.4 \%$ & $46 \%$ & $10.5 \%$ \\
\hline
\end{tabular}


By Parents:

Table 5.

Percentage change in various elements of Self-Regulation in students as observed by parents

\begin{tabular}{lccc}
\hline \multicolumn{1}{c}{ ELEMENTS } & INCREASE & DECREASE & NO CHANGE \\
\hline Trustworthiness & $35 \%$ & $55 \%$ & $10 \%$ \\
Adaptability & $54 \%$ & $38 \%$ & $8 \%$ \\
Conscientiousness & $50 \%$ & $40 \%$ & $10 \%$ \\
Innovativeness & $50.5 \%$ & $41.4 \%$ & $8.4 \%$ \\
Seif Control & $31.1 \%$ & $58.9 \%$ & $10 \%$ \\
Mean $\%$ & $44.1 \%$ & $46.6 \%$ & $9.3 \%$ \\
\hline
\end{tabular}

\subsection{Self-Motivation}

By Students:

Table 7.

Percentage change in various elements of Self-Motivation in students

\begin{tabular}{lccc}
\multicolumn{1}{c}{ ELEMENTS } & INCREASE & DECREASE & NO CHANGE \\
\hline Achievement & $52.9 \%$ & $30.9 \%$ & $16.2 \%$ \\
Commitment & $38.8 \%$ & $49.6 \%$ & $11.6 \%$ \\
Initiative & $54.7 \%$ & $35.3 \%$ & $10 \%$ \\
Optimism & $51.4 \%$ & $32.1 \%$ & $16.5 \%$ \\
Mean $\%$ & $49.4 \%$ & $36.9 \%$ & $13.5 \%$ \\
\hline
\end{tabular}

By Parents:

Table 8.

Percentage change in various elements of Self-Motivation in students as observed by parents

\begin{tabular}{lccc}
\hline \multicolumn{1}{c}{ ELEMENTS } & INCREASE & DECREASE & NO CHANGE \\
\hline Achievement & $55.2 \%$ & $26.5 \%$ & $18.3 \%$ \\
Committment & $35.3 \%$ & $48.6 \%$ & $16.1 \%$ \\
Initiative & $50 \%$ & $35.4 \%$ & $14.6 \%$ \\
Optimism & $56 \%$ & $28 \%$ & $16 \%$ \\
Mean $\%$ & $49.1 \%$ & $34.6 \%$ & $16.2 \%$ \\
\hline
\end{tabular}

\subsection{Social Awareness}

By Students:

Table 10.

Percentage change in various elements of Social Awareness in students

\begin{tabular}{|c|c|c|c|}
\hline ELEMENTS & INCREASE & DECREASE & NO CHANGE \\
\hline Empathy & $58.4 \%$ & $32.1 \%$ & $9.5 \%$ \\
\hline Diversity & $43.2 \%$ & $47.1 \%$ & $9.4 \%$ \\
\hline Mean \% & $50.8 \%$ & $40 \%$ & $9.5 \%$ \\
\hline
\end{tabular}

By Parents:

Table 11.

Percentage change in various elements of Social Awareness in students as observed by parents

\begin{tabular}{lccc}
\hline \multicolumn{1}{c}{ ELEMENTS } & INCREASE & DECREASE & NO CHANGE \\
\hline Empathy & $52.5 \%$ & $37.5 \%$ & $10 \%$ \\
Diversity & $40.6 \%$ & $48.5 \%$ & $10.9 \%$ \\
Mean $\%$ & $46.5 \%$ & $43 \%$ & $10.5 \%$ \\
\hline
\end{tabular}




\subsection{Social Skills}

By Students:

Table 13.

Percentage change in various elements of Social Skills in students

\begin{tabular}{lccc}
\hline \multicolumn{1}{c}{ ELEMENTS } & INCREASE & DECREASE & NO CHANGE \\
\hline Communication & $32.6 \%$ & $44.2 \%$ & $23.2 \%$ \\
Leadership & $55.3 \%$ & $34.5 \%$ & $10.2 \%$ \\
Conflict Management & $58.6 \%$ & $31.6 \%$ & $9.8 \%$ \\
Building Bonds & $60.3 \%$ & $28.8 \%$ & $10.9 \%$ \\
Team Coagulation & $58.8 \%$ & $31.2 \%$ & $10 \%$ \\
Mean $\%$ & $53.1 \%$ & $34 \%$ & $12.8 \%$ \\
\hline
\end{tabular}

By Parents:

Table 14.

Percentage change in various elements of Social Skills in students as observed by parents

\begin{tabular}{lccc}
\hline ELEMENTS & INCREASE & DECREASE & NO CHANGE \\
\hline Communication & $42.9 \%$ & $46.9 \%$ & $10.2 \%$ \\
Leadership & $58 \%$ & $29 \%$ & $13 \%$ \\
Conflict Management & $53.3 \%$ & $32.7 \%$ & $14 \%$ \\
Building Bonds & $63.3 \%$ & $22.5 \%$ & $14.2 \%$ \\
Team Coagulation & $60.5 \%$ & $24.7 \%$ & $14.8 \%$ \\
Mean $\%$ & $55.6 \%$ & $31.2 \%$ & $13.2 \%$ \\
\hline
\end{tabular}

\section{Interpretation}

As the Questionnaire survey contained questions related to various attributes of Emotional Intelligence, data in \% was Statistically Analysed using Mean Descriptive Statistics.

\subsection{Self-Awareness}

1) According to $56.7 \%$ students and $50.5 \%$ parents, Emotional Awareness of students increased during pandemic.

2) According to $53.6 \%$ students and $50 \%$ parents, there was an increase in Self-Assessment.

3) According to $56.4 \%$ students and 59.7\% parents, there was increase in Self Confidence of Adolescents.

Overall, there was an increase in Self Awareness by $55.5 \%$

\subsection{Self-Regulation}

1) According to $51.1 \%$ students and $55 \%$ parents, Trustworthiness decreased during pandemic.

2) According to $46.4 \%$ students and 54\% parents Adaptability showed upward trend during these tough times.

3) $48.7 \%$ students and $50 \%$ parents reported increase in Conscientiousness.

4) According to $55.4 \%$ students and $50.5 \%$ parents reported upward trend for Innovativeness.

5) According to $60 \%$ students and $58.9 \%$ parents there was decrease in Self Control.

Overall, there was a decrease in level of Self-Regulation.

\subsection{Self-Motivation}

1) According to $52.9 \%$ students and $55.2 \%$ parents reported increase in levels of Achievement.

2) According to $49.6 \%$ students and $48.6 \%$ parents, there was decrease in levels of Commitment. 
3) $54.7 \%$ students and 50\% parents showed increase in levels of taking Initiative.

4) Levels of Optimism showed upward trend by $51.4 \%$ students and $56 \%$ parents.

Overall, there was an increase in levels of Self-Motivation by $49.4 \%$

\subsection{Social Skills}

1) $44.2 \%$ students and $46.9 \%$ parents showed decrease in levels of Communication.

2) $55.3 \%$ students and $58 \%$ parents showed increase in Leadership during pandemic.

3) $60.3 \%$ students and $63.5 \%$ parents reported increase in Building Bonds.

4) $58.6 \%$ students and $53.3 \%$ parents reported increase in Conflict Management.

5) $58.8 \%$ students and $60.5 \%$ parents agreed to increase in Team Coagulation.

Overall, there was an increase in Social Skills by $53 \%$.

\subsection{Social Awareness}

1) According to $58.4 \%$ students and $52.5 \%$ parents there was increase in Empathy.

2) $47.4 \%$ Students and $48.5 \%$ parents reported decrease in levels of Diversity.

Overall, there was an increase in Social Awareness by $50.8 \%$.

\section{Result and Discussion}

From above interpretation, it is shown that during pandemic, all attributes of Social Intelligence have shown increase except one major attribute- Self Regulation. It has undergone a decrease during pandemic. Elements of Self-Regulation; Trust worthiness and Self Control have decreased of an individual.

One Element of Self-Motivation: Commitment has also deceased during these crucial times. Levels of Communication, Element of Social Skills has shown downward trend. Element of Social Awareness; Diversity has decreased during pandemic.

From Survey-2, reasons for decreased Self Control, Trustworthiness, Communication, Commitment and Diversity among adolescents are following;

1) Health issues of self or loss of near and dear ones

2) Decreased socialization and decreased sports activity

3) Financial problems or loss of job of parents

4) New work adaptation

5) New normal at home

6) Uncertainty of future

\section{Conclusion}

The Covid-19 pandemic is proving to be the greatest test of Emotional Intelligence among adolescents. These trying days of the pandemic have highlighted the importance of adolescents' Emotional Intelligence. Future uncertainty, stress, anxiety, home schooling, getting used to new forms of communication are all testing them in different ways. Though adolescents need to improve their self-control, Communication, Commitment and Diversity, some of the very important attributes of our emotions, they have been able to navigate their emotions well during this tough times. Increased levels of empathy, optimism shows that this pandemic has opened our hearts, made us more sensitive to others and our environment. Increased levels of Achievement, Initiative and Innovativeness proves that adolescents did get new ways to show their abilities, which indirectly helped in increasing their selfconfidence. 


\section{Acknowledgement}

This paper is an output of a study done to understand the changes in emotions of adolescents during this unprecedented time. I would like to thank the teachers, staff, and students of the senior wing of my school who all contributed to the study. I cannot forget to mention the parents of these students who were always ready to share behavioural experiences of their ward with me, which was of great help in my project.

I would also want to thank my son and my sister who motivated and helped me in numerous ways, be it in writing the paper or just by being there for me for the entirety of this 'experiment.'

\section{References}

Abrol, D.N. A Study of Achievement Motivation in Relation intelligence, Vocational interests, Achievement, Sex and Socio-Economic status, Delhi University, 1977

Adetayo, Janet O. and Kiadese, Adeola L. "Emotional Intelligence and Parental Involvement as Predictors of Students' Achievement in Financial Accounting." American Journal of Social and Management Sciences, vol. 2, no. 1, 2011, pp. 21-25.

Arshad Ali Bhat. "Emotional Intelligence of Higher Secondary School Students with Respect to Their Gender.” The International Journal of Indian Psychology, vol. 5, no. 1, 2017.

Asghar Mohamadi,2020, Emotional Intelligence and Emotional Stability in crisis, Volume 6 (4)-127, pp.1-5

Azita Joibari and Niloufar Mohammadtaheri. "The Study of Relation Between Emotional Intelligence and Students'.” Academic Achievement of High Schools in Tehran City, Procedia - Social and Behavioral Sciences, vol. 29, 2011, pp. 1334-1341

Goleman, Daniel. Emotional Intelligence: Why it Can Matter More Than IQ. Bantam Books, New York, 1996

Kumar, M. "A Study on the Emotional Intelligence of Higher Secondary School Students." Shanlax International Journal of Education, vol. 8, no. 3, 2020, pp. 114-11

Mayer, J and Salovey, P. "What is Emotional Intelligence?." Emotional Development and Emotional Intelligence Basic Books, edited by Salovey, P. and Sluyter, D.J, New York, 1997

Mayer, J.D and Salovey, P. "The Intelligence of Emotional Intelligence." Intelligence, vol. 17, no. 4, 1993, pp. 433-442.

Peter Salovey and Daisy Grewal, The Science of Emotional Intelligence, Source: Current Directions in Psychological Science, Vol. 14, No. 6 (Dec., 2005), pp. 281-285

Peter Salovey, John D. Mayer, David Caruso and Seung Hee Yoo: The Positive Psychology of Emotional Intelligence, Source: Counterpoints, Vol. 336, Emotional Intelligence: Perspectives on Educational and Positive Psychology (2008), pp. 185-208

Rajendra Prasad Das and Tapas Lata Sahu. "Relationship between Emotional Intelligence and Gender Difference: An Empirical Study." Prabandhan: Indian Journal of Management, vol. 8, no. 9, 2015

Salovey, P and Mayer, J.D. "Emotional Intelligence." Imagination, Cognition, and Personality, vol. 9, no. 3, 1990, pp. 185-211

S. Anitha Devi, Assessing Emotional Intelligence: Academic Performance \& Overall Personality Development, Source: Indian Journal of Industrial Relations, Vol. 48, No. 2 (October 2012), pp. 354-367 